\title{
MAPEAMENTO DA LINHA DE COSTA E AVALIACEÃO DA VULNERABILIDADE E SUSCEPTIBILIDADE À EROSÃO COSTEIRA ENTRE A FOZ DO RIO SÃO JOÃO E A FOZ DO RIO UNA - CABO FRIO/RJ
}

\author{
Coastal line mapping and vulnerability and susceptibility assessment \\ the coastal erosion between the mouth of the São João River \\ and the mouth of the River Una - Cabo Frio/RJ \\ Leonardo Quitanilha de Castro', Thaís Baptista da Rocha ${ }^{2}$, Rosemary Vieira ${ }^{3}$ \\ ${ }^{1}$ Mestrando em Geografia, Universidade Federal Fluminense - UFF, Bolsista Capes. Rua Silvana da Costa, $\mathrm{n}^{\circ}: 693$, \\ Barroco - Itaipuaçú, Maricá, RJ. CEP: 24.936-600 - leonardoquintanilha@id.uff.br * \\ ${ }^{2}$ Professora Adjunta, Universidade Federal Fluminense - UFF. Rua 17 de Novembro, $n^{\circ}$ : 20, Praia de Itaipuaçú, Maricá, \\ RJ. CEP: 24.963-770 - thaisbaptista@id.uff.br \\ ${ }^{3}$ Professora Associada, Universidade Federal Fluminense - UFF. Bolsista Produtividade 2 - CNPq. Condomínio Orla \\ 500, Rua Machado de Assis, n: 22, Tamoios, Cabo Frio, RJ. CEP: 28.929-400 - rosemaryvieira@id.uff.br
}

\section{RESUMO}

O presente trabalho trata de uma avaliação da vulnerabilidade e susceptibilidade à erosão costeira através do uso de geoindicadores e do mapeamento da linha de costa entre a foz do rio São João e a do rio Una no município de Cabo Frio (RJ). Devido à ocorrência de eventos com ondas de alta energia, foram identificadas características erosivas em parte do arco praial, mesmo que tal praia não possua um quadro de erosão costeira constatada. A metodologia adotada envolve o uso de geoindicadores para a análise de dois pontos no arco praial, através do uso de uma série temporal de fotografias aéreas e imagens de alta resolução (anos 1970, 2005 e 2018) para a classificação do uso do solo da orla marítima e vetorização da linha de costa em ambiente SIG. Os resultados mostram que o ponto localizado mais ao norte do arco praial possui uma alta vulnerabilidade e susceptibilidade à erosão costeira, enquanto no ponto mais ao sul há uma baixa vulnerabilidade e susceptibilidade. Havendo um alto crescimento urbano e a intensificação da ocupação na orla marítima, com construções próximas ao perfil dinâmico praial, esta passa a sofrer ataque direto das ondas de alta energia. Em meio às possíveis alterações no clima, projetadas em estudos recentes, com elevação no nível médio do mar, maior frequência de eventos extremos, aumento da potência das ondas e ocupação massiva dos ambientes costeiros, estudos que embasem o planejamento de ocupação e gestão da orla marítima fazem-se necessários.

Palavras-chave: geoindicadores, praias arenosas, linha de costa, erosão costeira.

Recebido em: $13 / 11 / 2019$

Aprovado em: 26/06/2020

Publicado em: 30/01/2021 


\begin{abstract}
The present work carried out an assessment of vulnerability and susceptibility to coastal erosion through the use of geoindicators and the mapping of the coastline between the mouth of the São João river and the Una river, in Cabo Frio (Rio de Janeiro State). Due to high wave energy events, erosive characteristics were identified in part of the beach arch, even though such area does not have a verified coastal erosion scenario. The methodology involves the use of geoindicators for the analysis of two points in the beach arch: the use of a temporal series of aerial photographs and high-resolution images (1970, 2005 and 2018) for the classification of the land use of the seafront, and shoreline vectorization in GIS environment. The results show that in the northernmost point of the beach arch has a high vulnerability and susceptibility to coastal erosion, while in the southernmost point there is a low vulnerability and susceptibility. It is observed a high urban growth and intensification of occupation on the seafront, with buildings close to the beach dynamic profile, which can result in a direct attack from high energy waves. Amid the possible changes in climate projected in recent studies, such as increase in mean sea level, higher frequency of extreme events, increased wave power and the massive occupation of coastal environments, studies that support planning and management of waterfront occupation are required.
\end{abstract}

Keywords: geoindicators, sandy beaches, coastline, coastal erosion.

\title{
INTRODUÇÃO
}

As praias arenosas são ambientes dinâmicos que estão em constante mudança devido à ação de uma série de agentes oceanográficos, tais como a alternância na energia das ondas, o transporte litorâneo, a oscilação das marés, a variação do nível do mar, além de fatores antrópicos. Estes, por sua vez, podem alterar o balanço sedimentar, refletindo em alterações na entrada e na saída de sedimentos do sistema praial. Nesse sentido, podem condicionar processos costeiros de erosão ou acreção que tendem a ser perceptíveis nas escalas de eventos, histórica e até geológica (Cowell \& Thorn, 1994).

Sendo assim, a linha de costa torna-se uma feição sensível a esses processos, respondendo à alteração no balanço sedimentar do ambiente praial, o que acaba lhe conferindo um papel de destaque na ciência sobre estudos de erosão e progradação em áreas costeiras. Em termos físicos, a definição mais comum é dada por Boak e Turner (2005), onde a linha de costa é definida pela interseção entre o mar e o continente. Embora pareça simples, essa definição traz alguns desafios perante a prática do mapeamento da linha de costa, uma vez que essa "linha de interseção" sofre diariamente com a influência de agentes oceanográficos, como ondas e marés.

De forma similar, a orla marítima é definida como uma unidade geográfica inclusa na zona costeira, sendo delimitada pela faixa de interface entre o mar e a terra firme, caracterizando-se pelo equilíbrio morfodinâmico do ambiente, no qual fenômenos terrestres e marinhos interagem uns com os outros (Muehe, 2006). Sendo assim, como explicitado por Rocha, Fernandez e Nascimento (2013), os processos geológicos e oceanográficos possuem nítida importância no comportamento e na evolução desses ambientes costeiros, além de configurarem diversos tipos de orla como falésias, praias arenosas, planícies lamosas, manguezais, entre outros. 
Trabalhos recentes vêm utilizando técnicas de monitoramento da linha de costa no intuito de identificar áreas costeiras com vulnerabilidade à erosão e em riscos potenciais, a fim de entender mais sobre a dinâmica natural dessas áreas frente às forçantes que atuam na gênesis desses processos, através de sensoriamento remoto ou por levantamentos de dados in loco, fazendo uso de imagens de alta resolução, confecção de perfis de praia ou através de geoindicadores, como demonstram os trabalhos de Muehe, Fernandez, Bulhões e Azevedo (2011), Rocha, Fernandez e Nascimento (2013), Magalhães (2018) e Luijendjk et al. (2018).

Nesse sentido, estudos sobre as mudanças da posição da linha de costa têm se tornado essenciais para a gestão da orla marítima e da zona costeira, justificados principalmente pelos prejuízos causados pela erosão costeira, bem como pelos possíveis cenários de aumento do nível do mar devido às alterações climáticas nesse século e/ou aumento da frequência e magnitude das ressacas, conforme tem sido apontado pelo Intergovernmental Panel on Climate Change - IPCC (2019).

Com isso, devido aos relatos acerca de eventos extremos com características erosivas na orla marítima de Unamar, localizada no município de Cabo Frio (RJ), o presente trabalho tem como objetivo principal a análise do posicionamento da linha de costa da orla marítima de Unamar em uma série temporal de 48 anos, assim como a avaliação da vulnerabilidade e da susceptibilidade física da orla marítima à erosão costeira por meio de geoindicadores. A fim de constatar o avanço da urbanização na área de estudo, uma análise da urbanização na orla marítima foi realizada pelo mapeamento do uso do solo para a série temporal em questão.

\section{MATERIAL E MÉTODOS}

\section{Área de estudo}

A área de estudo localiza-se no litoral oriental do Rio de Janeiro (Figura 1A), no município de Cabo Frio, entre a foz do rio São João e a foz do rio Una (Figura 1B), havendo dois pontos de análise enumerados de 1 a 2, de norte a sul, ao longo do arco praial (Figura 1C). Nesses pontos serão analisados o posicionamento da linha de costa e suas respectivas vulnerabilidades e susceptibilidades à erosão costeira, sendo o mapeamento do uso do solo para toda a orla marítima do arco praial.

O embaiamento do rio São João constitui um segmento bem individualizado dominado a partir da desembocadura do rio São João em direção ao cabo Búzios pela deposição de sedimentos finos de origem fluvial, diminuindo substancialmente a declividade da antepraia e definindo o estado morfodinâmico do arco praial que, de refletivo a norte (Figura 2), passa para dissipativo (Figura 3) a sul da desembocadura (Fernandez \& Muehe, 1998). 


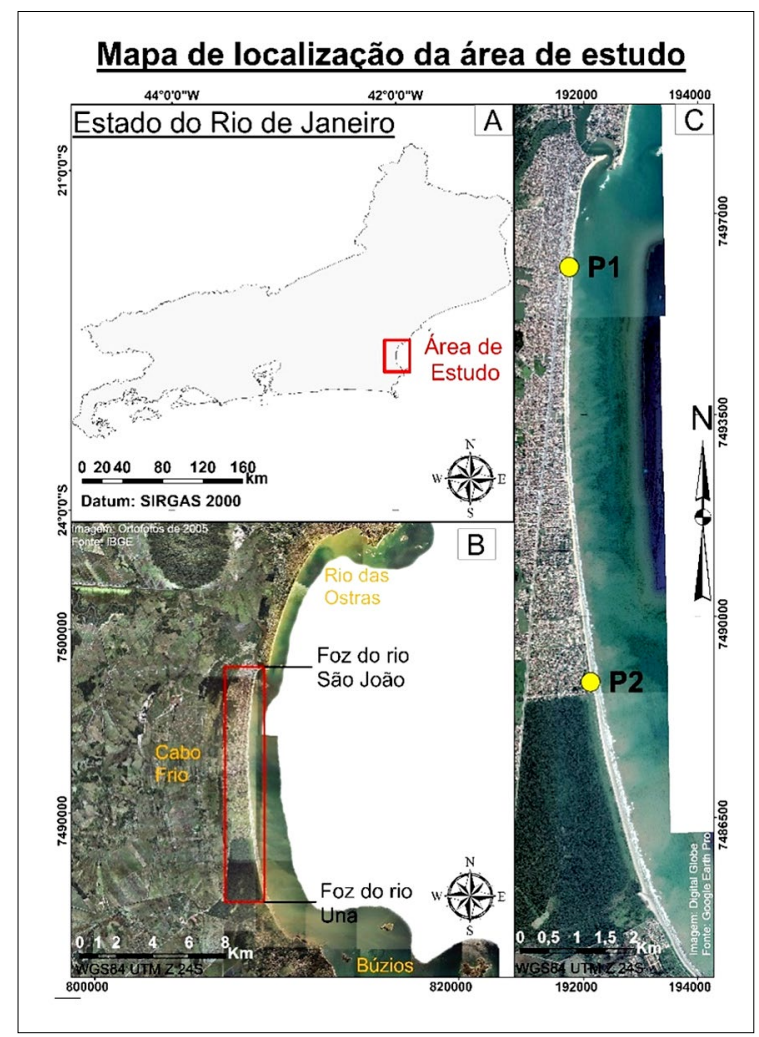

Figura 1 - Localização da área de estudo (A), no embaiamento do rio São João, junto com os municípios adjacentes e desembocaduras fluviais do rio São João e rio Una (B), e a disposição dos pontos de análise (C). Notar o padrão de ocupação concentrado na orla marítima

Fonte: dados do autor.

Figura 2 - Perfil praial emerso do ponto de análise 1 (norte do arco praial), praia com característica intermediária refletiva e presença de escarpa erosiva $(8 / 10 / 2017)$

Fonte: dados do autor.
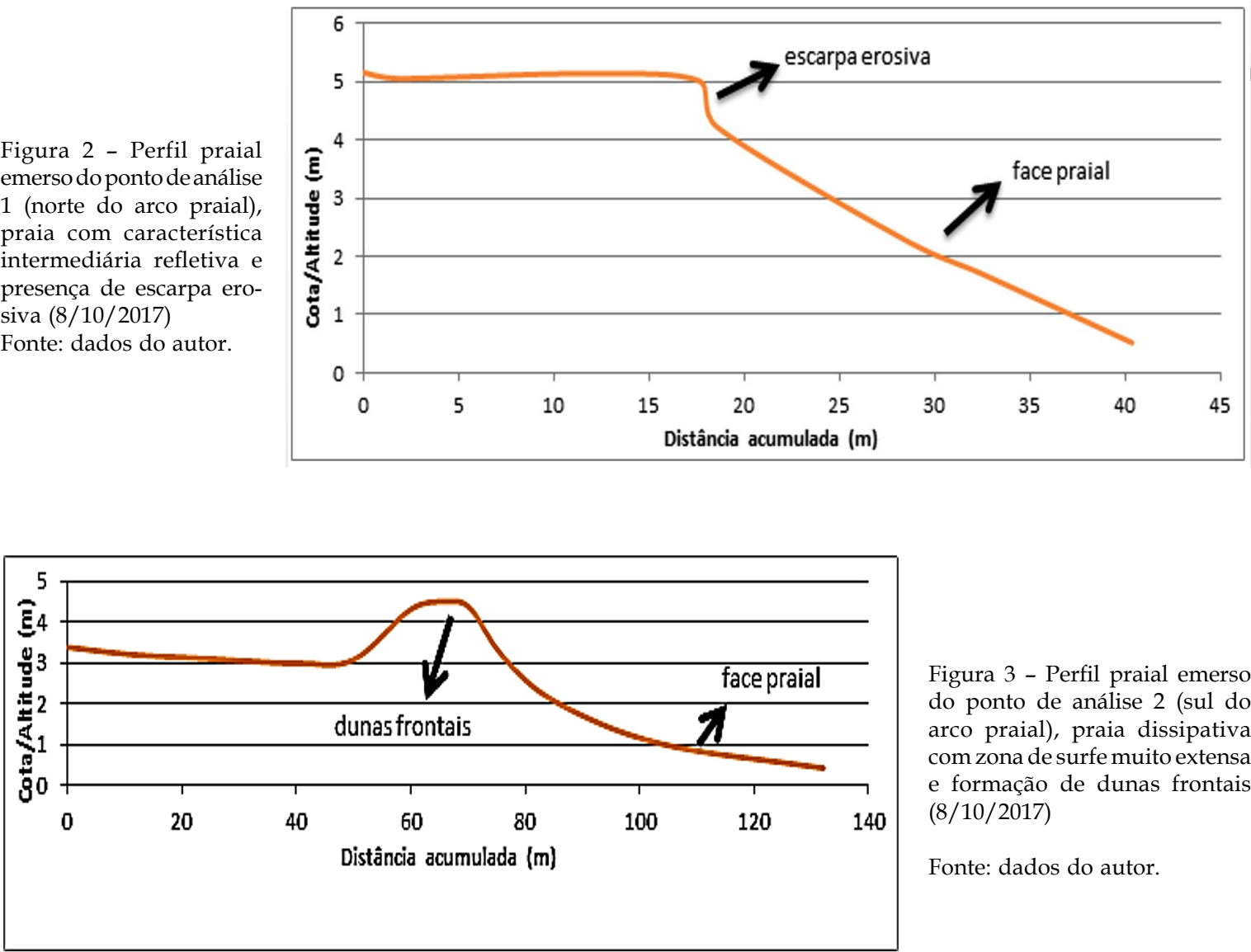

Figura 3 - Perfil praial emerso do ponto de análise 2 (sul do arco praial), praia dissipativa com zona de surfe muito extensa e formação de dunas frontais $(8 / 10 / 2017)$

Fonte: dados do autor. 
Na obra Erosão e progradação do litoral brasileiro (Muehe, 2006) há uma compilação de mapeamentos organizados por estados costeiros, que trazem informações como: a caracterização geomorfológica (praias arenosas, costão, manguezal, planície, dunas, falésia); o estado morfodinâmico da praia (dissipativa, intermediária, refletiva); o grau de exposição à energia de ondas (exposto, semiexposto, abrigado); e o grau de erosão costeira (forte, fraco, médio). Cabe ressaltar que, de forma geral, esta última informação foi estabelecida de maneira predominantemente qualitativa, isto é, sem o mapeamento em planta da dinâmica na linha de costa, utilizando imagens de alta resolução espacial.

Ressalta-se também que, no mapeamento qualitativo realizado por Muehe (2006), não há indicativos de erosão costeira para a área de estudo do presente trabalho, logo de alteração da linha de costa (Figura 4). Porém, recentemente, ataques das ondas durante eventos de ressaca e de maré alta têm produzido a destruição do calçadão e quiosques (Figura 5). Além disso, a respectiva área apresenta um padrão de ocupação denso na orla marítima, cujas edificações muitas vezes estão a menos de $50 \mathrm{~m}$ da praia, configurando um real potencial de risco e vulnerabilidade.

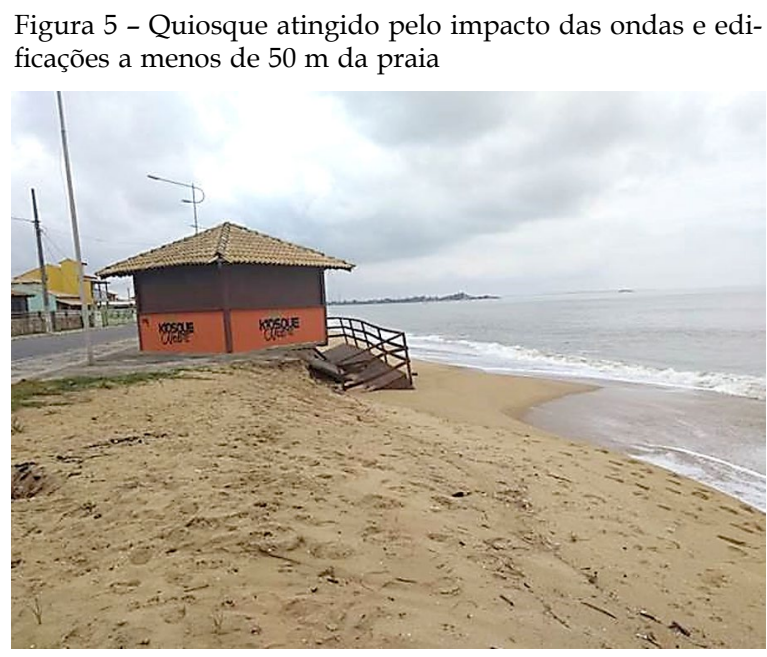

Fonte: acervo pessoal.

Klumb-Oliveira (2015) demonstrou que o clima de ondas para o litoral sudeste fluminense é caracterizado pelo predomínio de ondas provenientes do quadrante E-SE-S. As ondas são provenientes do quadrante E de baixa a média energia, com altura de ondas
Figura 4 - Grau de erosão costeira baseado em Muehe (2006). Notar ausência de dados na localidade de Unamar

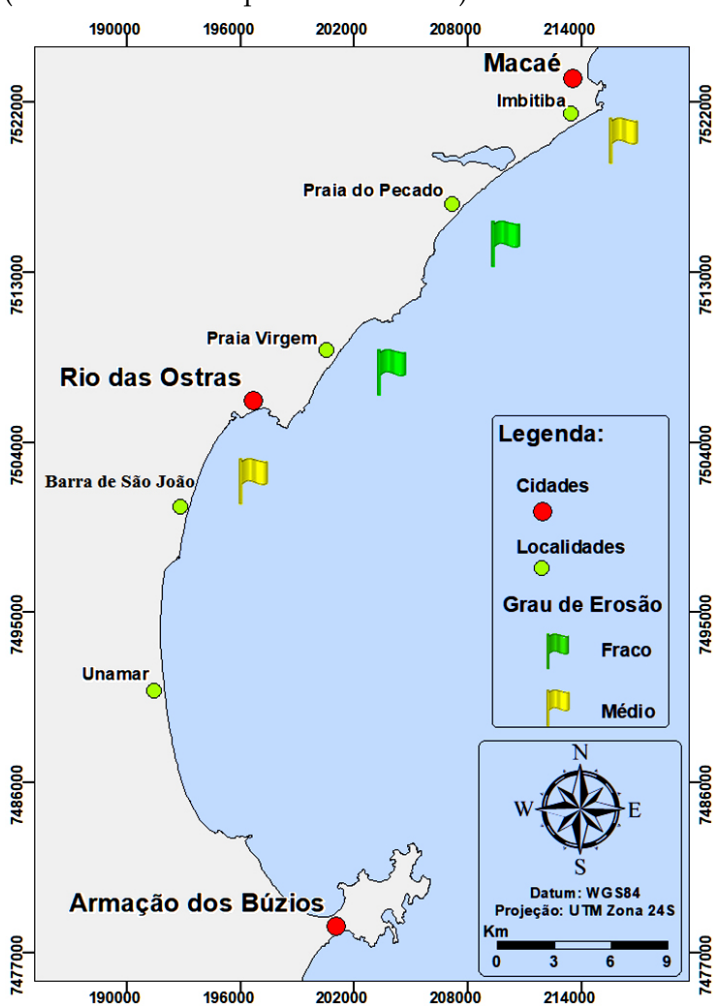

Fonte: adaptado de Muehe (2006).

\section{(1)


entre $1 \mathrm{~m}$ e $2 \mathrm{~m}$, menor período de pico e concentradas entre os meses de primavera e verão, associadas à influência do Anticiclone do Atlântico Sul (ASAS). Por conseguinte, ondas com maiores períodos e alturas superiores a $2 \mathrm{~m}$ são provenientes do quadrante $S$, concentrando-se entre o outono e o inverno, sendo associadas à passagem de sistemas frontais e ciclones extratropicais.

Bulhões et al. (2014) sugeriram a temporada de ondas provenientes de tempestades para o litoral fluminense para os meses entre abril e setembro, e, quando comparados aos dados de Klumb-Oliveira (2015), mostram-se coerentes. O clima de ondas exposto por Klumb-Oliveira (2015) considerou um período de 34 anos, tendo o recorte temporal do ano de 1979 ao ano de 2013 e seus dados de ondas foram obtidos a partir de uma simulação gerada no modelo Wavewatch III, demonstrados através da Figura 6.

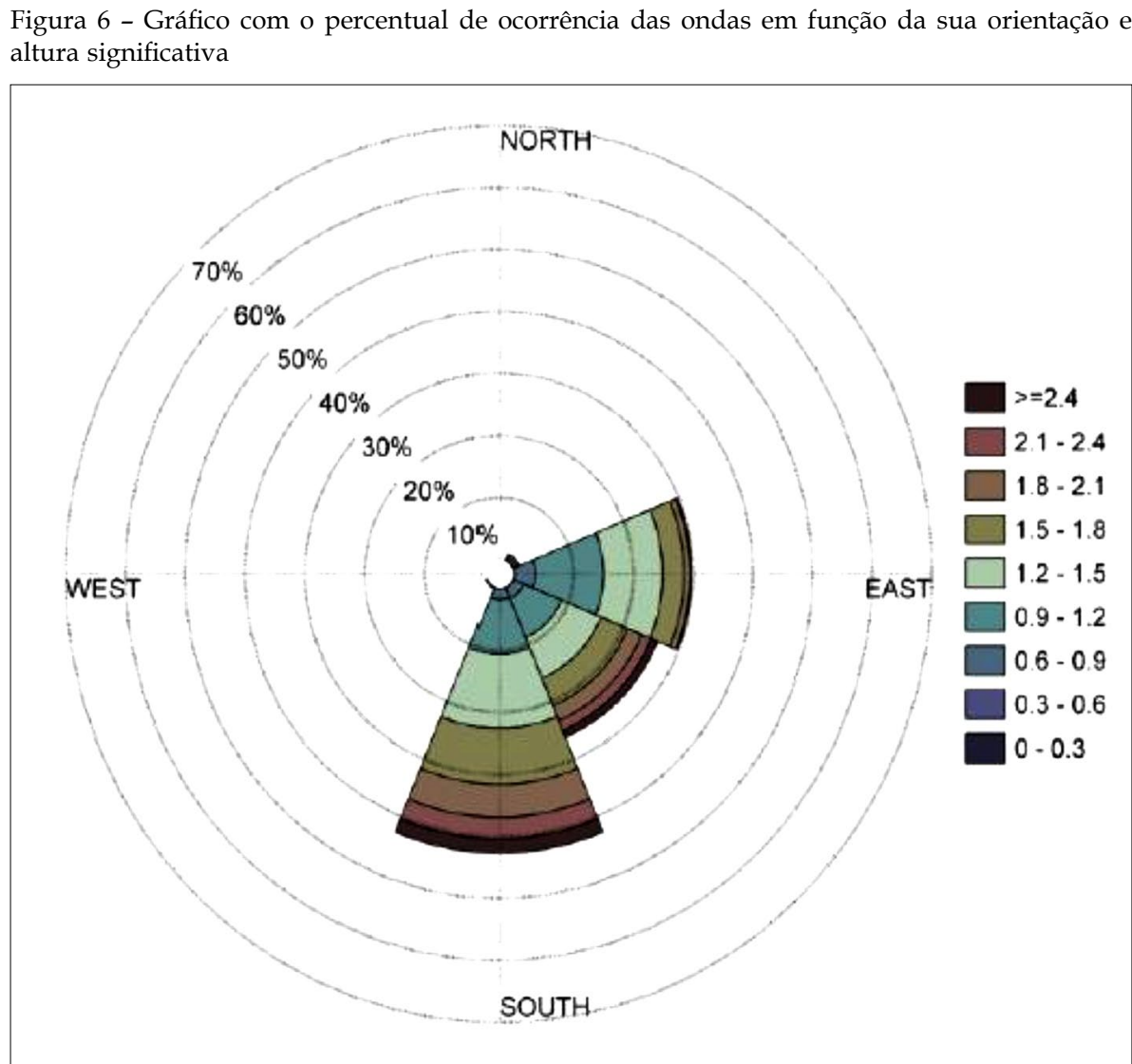

Fonte: Klumb-Oliveira (2015).

\section{METODOLOGIA}

O mapeamento de susceptibilidade buscou representar a incidência espacial de um processo perigoso, assim como em Magalhães (2018), com a proposta de mapear a propensão de uma área a ser afetada pela erosão costeira, sendo avaliada através dos fatores de predisposição para a ocorrência desse processo. Os geoindicadores utilizados para avaliar os fatores de predisposição à erosão costeira são os baseados em Bush, Neal, Young e Pilkey (1999), Souza, Bulhões e Amorim (2005) e Rocha, Fernandez e Nascimento (2013) e adaptados de Magalhães (2018), sendo eles: grau de exposição da praia (1); vegetação (2); 
altura das dunas frontais (3); largura da berma (4); escarpas (5); exumação de arenito ou beach rock (6); e estruturas danificadas ou de proteção (7). Esses geoindicadores foram organizados a partir de informações qualitativas que correspondem a três classes relacionadas ao grau de susceptibilidade: alto, médio e baixo (Quadro 1).

Esse quadro foi preenchido nos dois pontos de análise em um trabalho de campo realizado na área de estudo no ano de 2017. Para transformar o dado qualitativo em dado quantitativo foram dados pesos às classes de geoindicadores, de maneira que as classes referentes à susceptibilidade baixa tivessem peso 1; as classes de susceptibilidade média, peso 2; e as classes de susceptibilidade alta, peso 3.

Para definir a amplitude das classes, foi utilizada a seguinte equação:

$$
a=\frac{L s-L i}{k}
$$

Onde:

$a$ : amplitude das classes

Ls: limite superior

Li: limite inferior

k: número de classes

No caso dos geoindicadores referentes à susceptibilidade, obteve-se $\mathrm{Ls}=21 ; \mathrm{Li}=7 ; \mathrm{k}$ $=5$; e $\mathrm{a}=2,8$. Nesse sentido, foram definidas as seguintes classes para o mapeamento de susceptibilidade:

- Muito baixa: 7-9

- Baixa: 10-12

- Média: 13-15

- Alta: 16-18

- Muita alta: 19-21

Para a identificação das áreas mais vulneráveis, foram avaliados como critério, além dos geoindicadores de susceptibilidade, a posição das edificações (8), o nível de artificialização da orla (9) e o tipo de uso e ocupação da orla (10). Com isso foi gerado um quadro no qual constam os critérios utilizados para compor os geoindicadores relativos tanto à susceptibilidade quanto à vulnerabilidade das áreas consideradas, como demonstra o Quadro 1.

Foram observadas (in situ) as posições das edificações em relação à distância do perfil dinâmico praial, de modo que as edificações encontradas na berma ou no topo da escarpa de pós-

Quadro1 - Geoindicadores de susceptibilidade e vulnerabilidade à erosão costeira

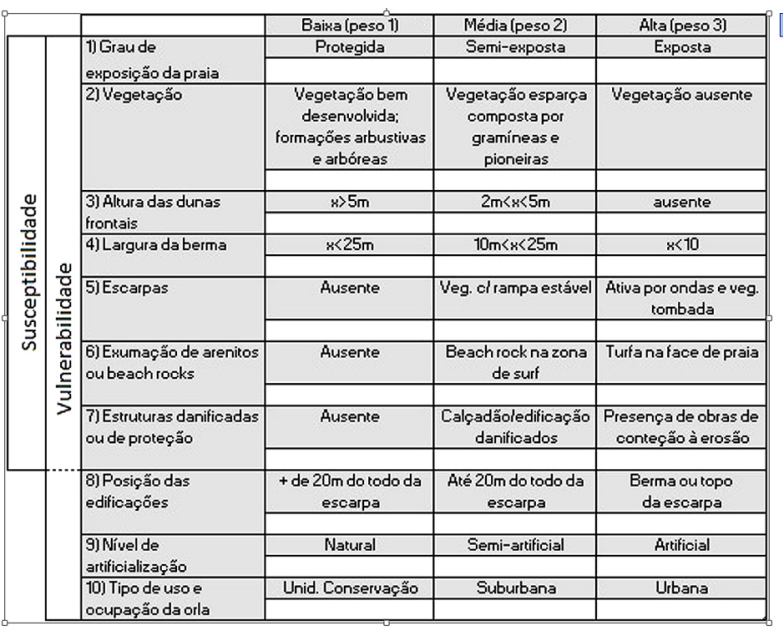

Fonte: adaptado de Magalhães (2018). 
praia ou topo da barreira fossem classificadas como de alta vulnerabilidade, uma vez que quanto mais próximo da dinâmica da praia, maiores podem ser os impactos e prejuízos decorrentes da erosão costeira. Edificações que estivessem a $20 \mathrm{~m}$ do topo da barreira ou escarpa e edificações que estivessem a mais de $20 \mathrm{~m}$ das mesmas foram enquadradas nas classes de média e baixa vulnerabilidade, respectivamente. Essa classificação tem como base as distâncias estabelecidas por Lins-de-Barros (2005), conforme mostra a Figura 7.

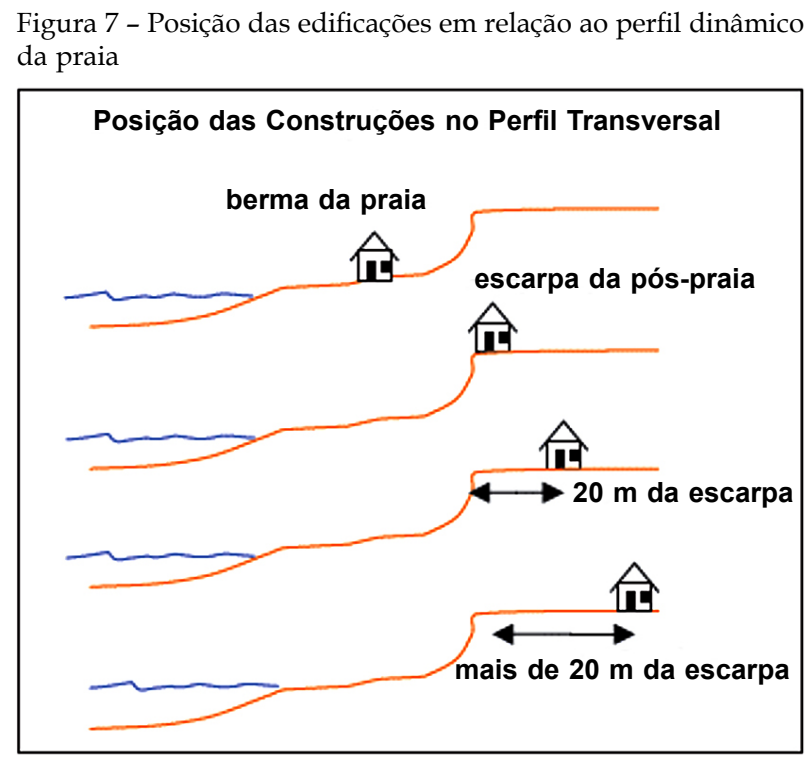

Fonte: Lins-de-Barros (2005).

A artificialização é um processo de transformação da paisagem natural, decorrente da alteração do espaço produzida pelo homem (Silva, 2007). Especificamente no caso da artificialização da orla, foi utilizada a classificação estabelecida no Projeto Orla, conforme mostra o Quadro 2. Entende-se que quanto mais artificial, menos chances de adaptação e resistência a praia e a orla podem ter, já que o alto adensamento de construções normalmente se dá a partir da supressão da vegetação de restinga e das dunas frontais. Além disso, presume-se que quanto maior o nível de artificialização da orla, maior podem ser os impactos e prejuízos.

Quadro 2 - Classes de nível de artificialização propostas pelo Projeto Orla

\begin{tabular}{|l|c|}
\hline \multicolumn{1}{|c|}{ CLASSE PROJETO ORLA } & CLASSES NÍVEL ARTIFICIALIZAÇÃO \\
\hline $\begin{array}{l}\text { Classe A: baixíssima ocupação, com paisagens } \\
\text { com alto grau de originalidade e baixo potencial } \\
\text { de poluição. }\end{array}$ & NATURAL \\
\hline $\begin{array}{l}\text { Classe B: tipos que apresentam de baixo a } \\
\text { médio adensamento de construções e poluição } \\
\text { residente, com indícios de ocupação recente, } \\
\text { paisagem parcialmente antropizadas e médio } \\
\text { potencial de poluição. }\end{array}$ & SEMI-NATURAL / SEMI-ARTIFICIAL \\
\hline $\begin{array}{l}\text { Classe C: médio a alto adensamento de } \\
\text { construções e poluição residentes, com } \\
\text { paisagem antropizadas, multiplicidade de usos } \\
\text { e alto potencial de poluição. }\end{array}$ & \\
\hline
\end{tabular}


Para a transformação dos dados qualitativos de vulnerabilidade em quantitativos, foi utilizada a mesma metodologia do mapeamento de susceptibilidade; entretanto, no caso da vulnerabilidade, obteve-se $\mathrm{Ls}=30 ; \mathrm{Li}=10 ; \mathrm{k}=5$; e $\mathrm{a}=4$. Nesse sentido, foram definidas as seguintes classes para o mapeamento de vulnerabilidade:

- Muito baixa: 10-14

- Baixa: 15-18

- Média: 19-22

- Alta: 23-26

- Muita alta: 27-30

Foram utilizadas fotografias aéreas do ano de 1970, obtidas na Diretoria de Recursos Minerais (DRM); ortofotos do ano de 2005, disponibilizadas pelo Instituto Brasileiro de Geografia e Estatística (IBGE); e imagens de satélite de 2018, da plataforma Google Earth Pro (Digital Globe). Todas as fotografias e imagens de satélite possuem entre 1,0 m e 0,75 $\mathrm{m}$ de resolução espacial, condizente com a escala de detalhe necessária para esse mapeamento. As imagens foram devidamente georreferenciadas, como exemplificado nas Figuras 8 e 9, obtendo um erro residual de até $1 \mathrm{~m}$, utilizando como base as ortofotos do IBGE datadas de 2005 para obtenção das coordenadas.

Figura 8 - Mapa ilustrando o georreferenciamento das imagens obtidas na DRM, geradas pelo voo da DEME em 1970

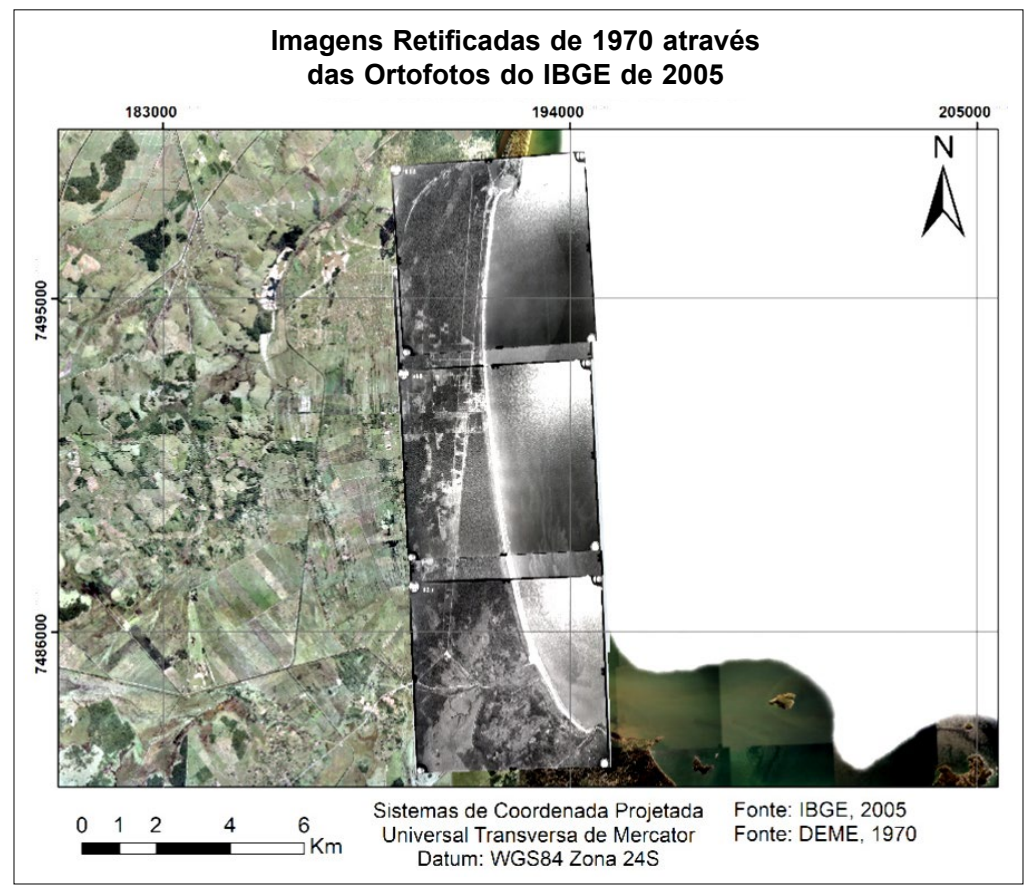


Figura 9 - Mapa ilustrando o georreferenciamento das imagens obtidas pelo Google Earth Pro, geradas pelo Digital Globe em 2018

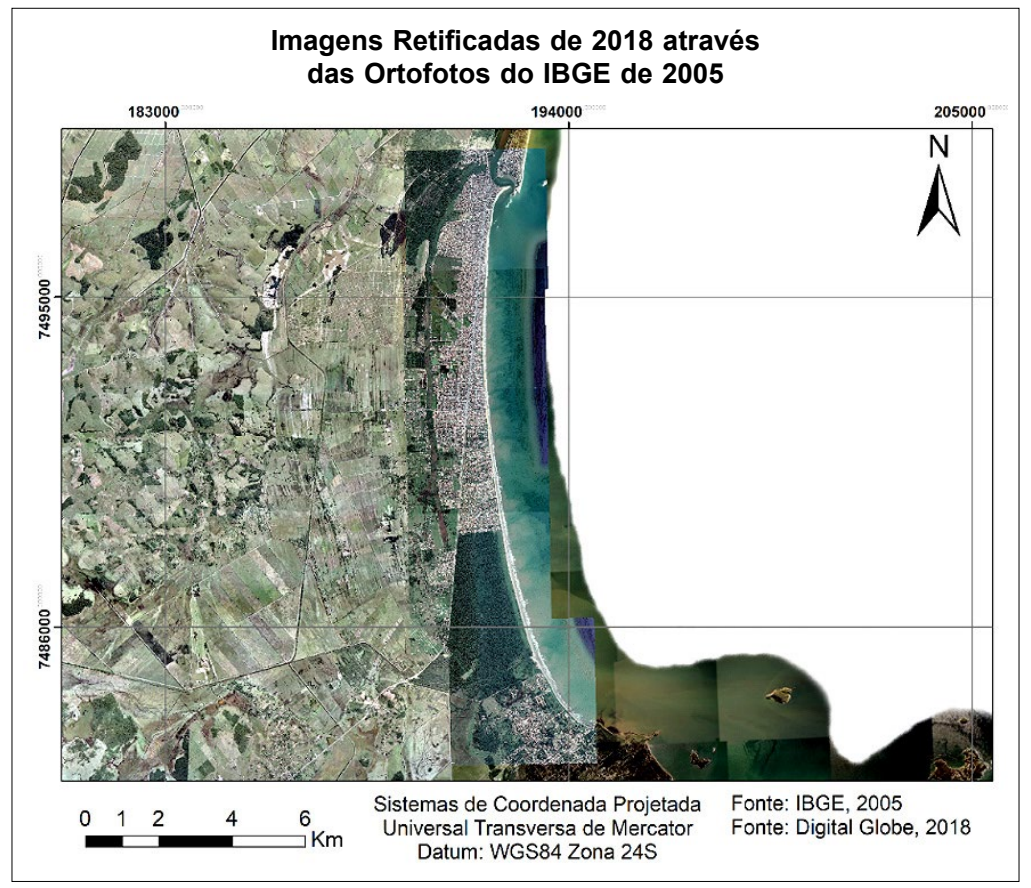

Através da obtenção de coordenadas de feições visíveis nas imagens passíveis de registro num dado sistema de referências, originaram-se os pontos de controles. Utilizaram-se como feições para obtenção dos pontos de controle: interseções de estradas e pontes, edificações, costões rochosos, meandros abandonados e feições antropizadas. A partir disso, foi executada a transformação das posições desses pontos de controle para o sistema de referência por meio de equações polinomiais de $1^{\mathrm{a}}$ e $2^{\mathrm{a}}$ ordem, variando a ordem da equação devido às características da imagem e dos números de pontos de controle disponíveis, onde foi utilizada a transformação geral afim no plano, com seis parâmetros básicos: dois fatores de escala, em X e Y; duas translações, em X e Y; um fator de rotação e um fator de inclinação. Esse procedimento foi executado por meio da ferramenta Georreferencing localizado na barra de ferramentas do software ArcGIS 10.4 em sua interface ArcMap, para a posterior vetorização da linha de costa e confecção dos mapas.

Pelo fato de a linha de costa ser dinâmica por natureza, para fins práticos, os investigadores costeiros adotam tipicamente o uso de indicadores da linha de costa, fazendo com que, na prática, a decisão sobre qual indicador da linha de costa usar em um local específico seja quase sempre determinada pela disponibilidade de dados (Boak \& Turner, 2005). Para a obtenção da linha de costa foi necessário escolher um indicador que atendesse às especificidades fisiográficas e morfodinâmicas da área, sendo este um recurso utilizado como um proxy para representar a real posição da linha de costa.

Os indicadores individuais da linha de costa, segundo Boak e Turner (2005), geralmente estão inseridos em uma das duas categorias a seguir: na primeira categoria os indicadores são baseados em uma característica costeira visualmente discernível, enquanto na segunda categoria são baseados em um datum específico da maré. Sendo assim, um indicador visualmente discernível é um recurso que pode ser visto fisicamente, por exemplo, uma linha anterior de maré alta ou o limite úmido/seco. Em contraste, o indicador da linha de costa baseado em um datum de maré é determinado pela interseção entre o perfil cos- 
teiro com uma elevação vertical específica, definida pelos constituintes das marés, e o nível médio do mar de uma área particular.

Dessa forma, para a vetorização da linha de costa utilizou-se como indicador substituto da mesma o limite da vegetação e, na sua ausência, o limite das construções antrópicas, devido ao fato de ser possível a identificação desses limites através dos dados disponíveis para a análise. Esses indicadores são, portanto, enquadrados na primeira categoria de acordo com o exposto por Boak e Turner (2005), como características costeiras visualmente discerníveis e não associados ao datum vertical. Essa vetorização foi realizada na escala de 1:1000, a fim de se obter um nível de detalhamento coerente para a identificação dos limites, tanto da vegetação quanto das construções antrópicas, por meio da criação de um shapefile no software ArcGis 10.4 em sua interface ArcMap.

Recentemente, uma terceira categoria de indicador de linha de costa começou a ser relatada na literatura, baseada na aplicação de técnicas de processamento de imagem para extrair recursos como proxy da linha de costa a partir de imagens costeiras digitais, que não são necessariamente visíveis para o olho humano (Aarninkhof; Caljouw \& Stive, 2000, apud Boak \& Turner, 2005). Luijendijk et al. (2018), fazendo uso do refinamento dessas técnicas de processamento digital de imagens, realizaram um mapeamento automatizado em escala global da linha de costa por meio da plataforma Google Earth Engine (GGE), abarcando uma série temporal de 33 anos (de 1984 a 2016); seus resultados são de acesso livre e estão disponíveis na plataforma DeltaresAquaMonitor (https:/ /aqua- monitor.appspot. com/?datasets=shoreline).

Com isso, será feita uma comparação dos resultados gerados pelo presente trabalho, o qual possui uma série temporal de 48 anos (de 1970 a 2018), em relação aos gerados por Luijendijk et al. (2018) para a mesma área de estudo. Luijendijk et al. (2018) apresentaram uma avaliação da ocorrência de praias arenosas e as taxas de mudanças no posicionamento da linha de costa, onde apontam que $24 \%$ das praias arenosas de todo o mundo estão em quadro de erosão a taxas que superam os $0.5 \mathrm{~m} /$ ano, enquanto $28 \%$ delas estão em acreção e $48 \%$ estão estáveis.

No Projeto Orla foram estabelecidos os limites genéricos da orla marítima como sendo: na zona marinha, a isóbata de $10 \mathrm{~m}$, profundidade na qual a ação das ondas passa a sofrer influência da variabilidade topográfica do fundo marinho, promovendo o transporte de sedimentos; na área terrestre, $50 \mathrm{~m}$ em áreas urbanizadas ou $200 \mathrm{~m}$ em áreas não urbanizadas demarcadas na direção do continente a da linha de preamar ou do limite final dos ecossistemas (ex.: feições de praia, dunas, restingas, entre outros) (Muehe, 2006).

Neste trabalho, usou-se a delimitação da orla marítima de 300 m, a partir da linha de costa, assim como em Piatto e Pollete (2012), sendo essa medida estabelecida a fim de englobar a área determinada pelo Projeto Orla. Foram utilizadas no presente trabalho 7 classes de uso e ocupação do solo, sendo elas: área antropizada (descaracterização da área por ações antrópicas); área urbana (ocupações proximais entre si); área urbana densa (adensamento de edificações); campo (áreas de pastagem ou predominantemente composta por gramíneas); solo exposto; vegetação (compreendida como vegetação arbórea ou florestal); e vegetação de restinga (marcada por vegetação pioneira, tipicamente reptante).

Dessa forma, foi realizado um buffer de $300 \mathrm{~m}$ a partir da linha de costa previamente vetorizada, o que culminou em uma área de aproximadamente $4 \mathrm{~km}^{2}$ para análise do uso do solo na orla marítima da presente área de estudo. Essa classificação foi realizada através do software ArcGIS 10.4 em sua interface ArcMap, utilizando a escala de 1:5000, tendo essa escala um nível de detalhamento satisfatório para a identificação visual das classes propostas. 


\section{RESULTADOS E DISCUSSÕES}

O mapa realizado para classificar a vulnerabilidade e susceptibilidade dos dois pontos de comparação da área de estudo, assim como o mapeamento da linha de costa para a série temporal anteriormente mencionada (1970/2005/2018), pode ser visto na Figura 10 e os dados de Luijendijk et al. (2018) podem ser vistos na Figura 11.

Por meio do uso dos geoindicadores a área do ponto 1 pode ser classificada como de alta vulnerabilidade e susceptibilidade à erosão costeira. É possível notar um adensamento das construções no arco praial e sua proximidade ao perfil dinâmico no ponto 1, assim como a presença rarefeita da vegetação de restinga, sendo uma área na qual a faixa de areia se mostra estreita e exposta ao ataque de ondas de alta energia (Figura 10). No ponto 2, as construções se mostram distantes do perfil dinâmico praial, com faixa de areia mais extensa quando comparada ao ponto 1, com presença de uma vegetação de restinga desenvolvida. É possível identificar em determinado ponto a formação de duna frontal, obtendose uma classificação de baixa vulnerabilidade e susceptibilidade.

No ponto 1, vemos que a linha de costa, quando analisada entre os anos de 1970 e 2005, avança em direção ao mar, afastando-se 12 m de sua posição inicial em 1970; entretanto, ao analisarmos o período entre 2005 e 2018, pode-se notar que a mesma recua em direção ao continente para uma posição muito similar à original de 1970 (Figura 10). Com isso, ao interpretarmos o período de 1970 a 2018, a linha de costa mostra-se, grosso modo, em uma posição inalterada, levando-nos a supor uma estabilidade para esse período. Enquanto no ponto 2 a linha de costa entre os anos de 1970 e 2005 recua cerca de $11 \mathrm{~m}$, entre 2005 e 2018 avança parcialmente até a sua posição inicial. No período de 1970 a 2018, este ponto não obteve uma recuperação tão similar da sua posição de linha de costa inicial quando comparado com o ponto 1, mas pode-se perceber que a linha de costa em determinado local atingiu essa posição inicial (Figura 10).

Figura 10 - Mapa de vulnerabilidade e susceptibilidade, junto com o afastamento em metros para os anos de 1970, 2005 e 2018 nos pontos 1 e 2

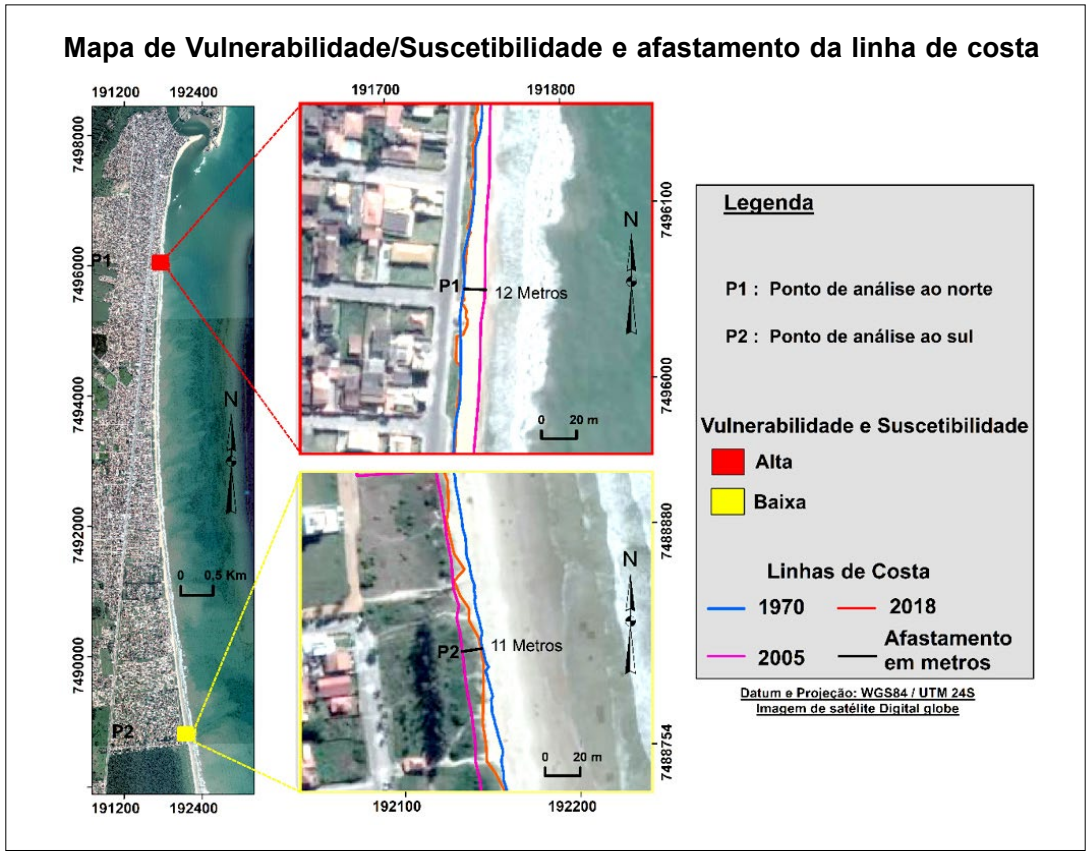


Tal variação, em ambos os pontos, obteve uma amplitude entorno de $10 \mathrm{~m}$. Quando comparado aos dados do gráfico elaborado por Luijendijk et al. (2018) (Figura 11), pode-se perceber, através da dispersão das posições de linha de costa, uma considerável variabilidade morfodinâmica. Essa variabilidade morfodinâmica possivelmente está associada à passagem de frentes frias com ondas de alta energia, tendo importante influência no posicionamento da linha de costa ao longo do tempo.

Podemos notar que os dados de Luijendijk et al. (2018) sugerem uma taxa de $-0.2 \mathrm{~m}$ por ano para o ponto 1 (Figura 11), estando, dessa forma, na classe de estabilidade para o período de 33 anos analisados. Para o ponto 2 obteve-se uma taxa de $0,5 \mathrm{~m}$ ao ano, estando, da mesma forma que o ponto 1 , na categoria de praias em estabilidade. Porém, como visto na Figura 5, o ponto 1 demonstra respostas a eventos de alta energia com características erosivas, apesar de ser considerada como uma praia estável.

Figura 11 - Gráfico de evolução histórica da linha de costa

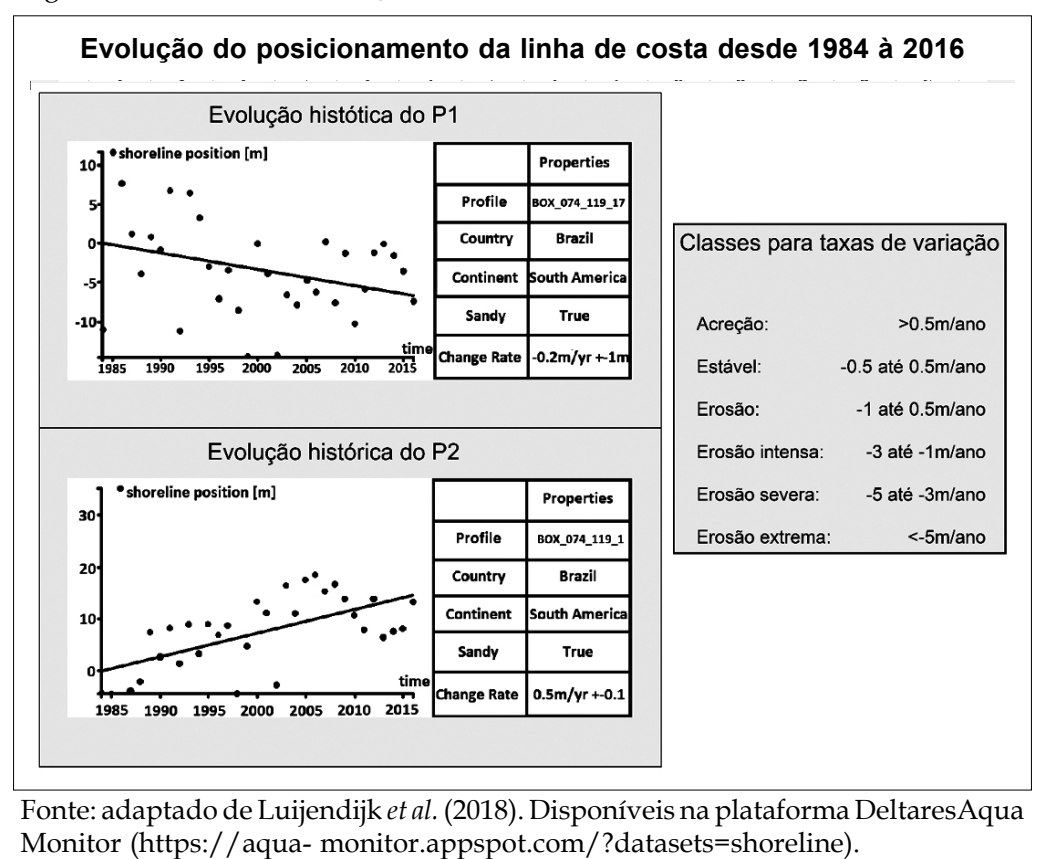

Recentemente, trabalhos vêm utilizando modelagens computacionais para complementar o entendimento sobre a propagação de ondas predominantes no embaiamento do rio São João, a fim de avaliar a exposição da costa às direções de ondas de tempestade e possíveis pontos de elevada energia (hot spots), assim como sua relação com o transporte de sedimentos (Azevedo, 2008; Muehe et al., 2011; Lins-de-Barros, 2010). Azevedo (2008) fez uso do software SisBaHiA (Sistema Base de Hidrodinâmica Ambiental) em seu Modelo de Propagação de Ondas simulando seis cenários distintos: ondas de nordeste, com características de altura $(\mathrm{H})$ e período $(\mathrm{T})$ das condições médias e extremas encontradas nos registros; onda de sudeste também em suas condições médias e extremas; e ondas de sul e sudoeste.

No resultado de propagação de ondas em condições extremas de nordeste, Azevedo (2008) observou distribuições de alturas significativas que variam entre 0,5 m e $1 \mathrm{~m}$, com exceção apenas ao norte do rio São João, fora dos limites da área de estudo do presente trabalho. Nas condições extremas de sudeste, são observadas, pontualmente, ondas com até $3 \mathrm{~m}$ entre a região em frente da desembocadura do rio São João (próximo ao ponto 1 do 
presente trabalho) e a região central da área de estudo do presente trabalho (Azevedo, 2008). Porém, de forma geral, as alturas variam entre $0,9 \mathrm{~m}$ e $1 \mathrm{~m}$ até a desembocadura do rio Una (próximo ao ponto 2 do presente trabalho), sendo influenciada pelo efeito de sombra do cabo Búzios (Azevedo, 2008).

Muehe et al. (2011) também fizeram uso do mesmo software (SisBaHiA) para a mesma área de estudo, analisando direções de ondas de nordeste e sul-sudeste sob condições extremas, demonstrando que grande parte do arco praial sofre, de forma pouco diferenciada, a influência das ondas de nordeste $\left(60^{\circ}\right)$, as quais são de direção mais frequentes. Nas condições extremas e de direção nordeste, Muehe et al. (2011) também identificaram o segmento de maior convergência de energia (hot spot) localizado pouco ao norte da desembocadura do rio São João, fora da área de estudo do presente trabalho, assim como Azevedo (2008). Já para ondas vindas de sul-sudeste, o cabo Búzios exerce um efeito de sombra sobre a metade sul do arco praial, enquanto apenas a área limitada e imediatamente após a foz do rio São João (próximo ao ponto 1 do presente trabalho) sofre a influência de ondas dessa direção (Muehe et al., 2011).

As ondas de direção nordeste não apresentam forte influência nas praias desse litoral, chegando com pouca altura e energia na linha de costa, e representam as condições mais frequentes, porém muito raramente adquirem altura superior a $2 \mathrm{~m}$ (Lins-de-Barros, 2010).

Para a modelagem realizada por Lins-de-Barros (2010), também foram consideradas condições extremas e médias para ressaltar os pontos de maior convergência de energia de ondas (hot spots). Os resultados da modelagem de ondas para diferentes condições de mar apontaram que as ondulações advindas de nordeste, leste e sudeste são as que mais influenciam o litoral deste segmento entre Cabo Frio e Rio das Ostras (Lins-de-Barros, 2010). Essa concentração de energia em determinados pontos do litoral (hot spots), segundo Linsde-Barros (2010), também ocorre com as ondas de sudeste que, apesar de incidirem obliquamente a linha de costa, apresentam alturas e períodos frequentemente mais elevados.

Na Figura 12 pode ser visto o mapa gerado com o buffer de $300 \mathrm{~m}$ feito para a classificação do uso do solo para a orla marítima da área de estudo. Conforme pode ser visto no mapa, no ano de 1970 não há muitos indícios de ocupação na orla marítima, a não ser pequenos pontos isolados no extremo norte e na parte central do arco praial, com a presença de áreas antropizadas entre eles, ou seja, onde já se pode notar a alteração na paisagem natural. Nota-se também um nítido aumento das ocupações e sua intensificação na orla marítima nos primeiros 35 anos (1970/2005) da série temporal analisada. Examinando o ano de 2005, vemos que há um adensamento na orla marítima do extremo norte do arco praial até sua parte central, ligando as duas áreas de seu arco praial, onde em 1970 já havia sinais de estruturas urbanas, e a existência de ocupações no setor centro-sul sem adensamento, junto com a ocorrência de preservação da vegetação, tanto florestal quanto de restinga, no setor sul do arco praial. Em 2018, vemos que o processo de adensamento das ocupações atinge a orla marítima por completo, exceto no setor sul, onde ainda se mantêm preservadas as vegetações naturais.

Através do gráfico de barras elaborado a partir dos dados referentes ao percentual de uso do solo na orla marítima, visto na Figura 13, pode-se perceber um aumento de aproximadamente $15 \%$ da área total se convertendo em área urbana de 1970 até o ano de 2005, juntamente com o surgimento da classe de área urbana densa representando mais de $40 \%$ da área total coberta na respectiva orla marítima para o ano de 2005. Para o ano de 2018 temos apenas a classe de área urbana densa, representando um significativo crescimento urbano, superando os $65 \%$ de área total coberta do solo na referida orla. 
Figura 12 - Classificação visual do uso do solo para os anos de 1970, 2005 e 2018 na orla marítima da área de estudo

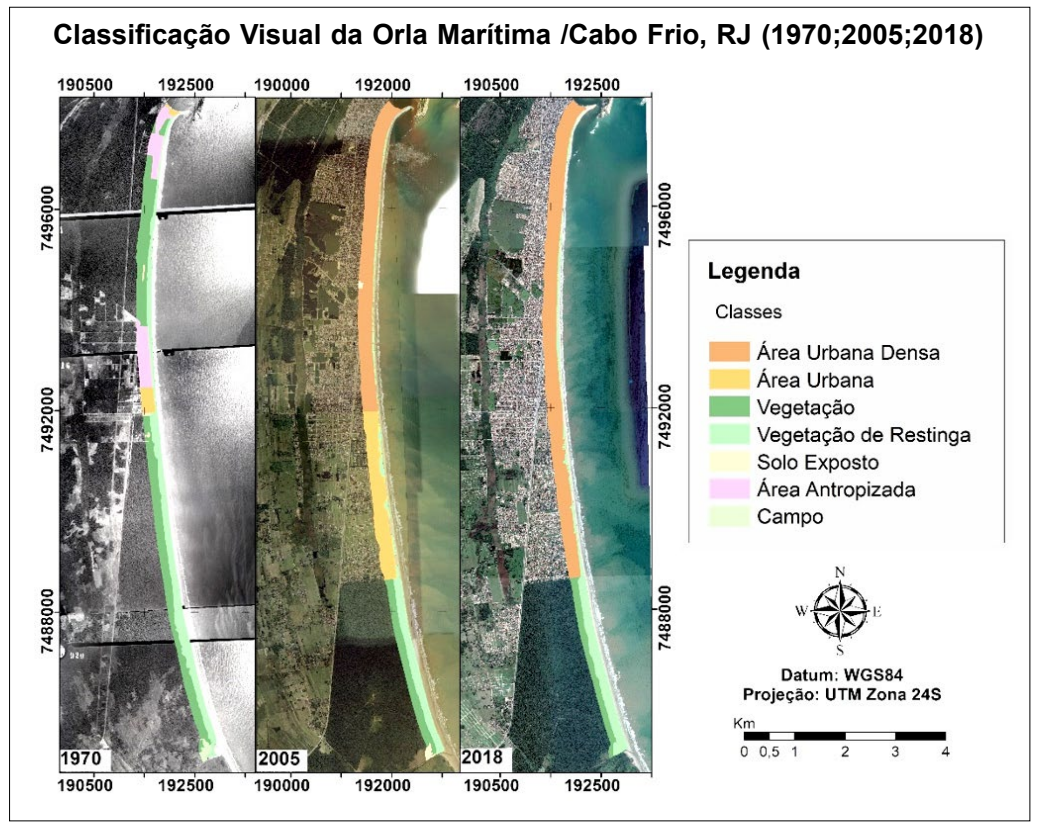

Figura 13 - Percentual de uso e cobertura do solo na orla marítima entre a foz do rio São João e a foz do rio Una (Cabo Frio, RJ) para os anos de 1970, 2005 e 2018

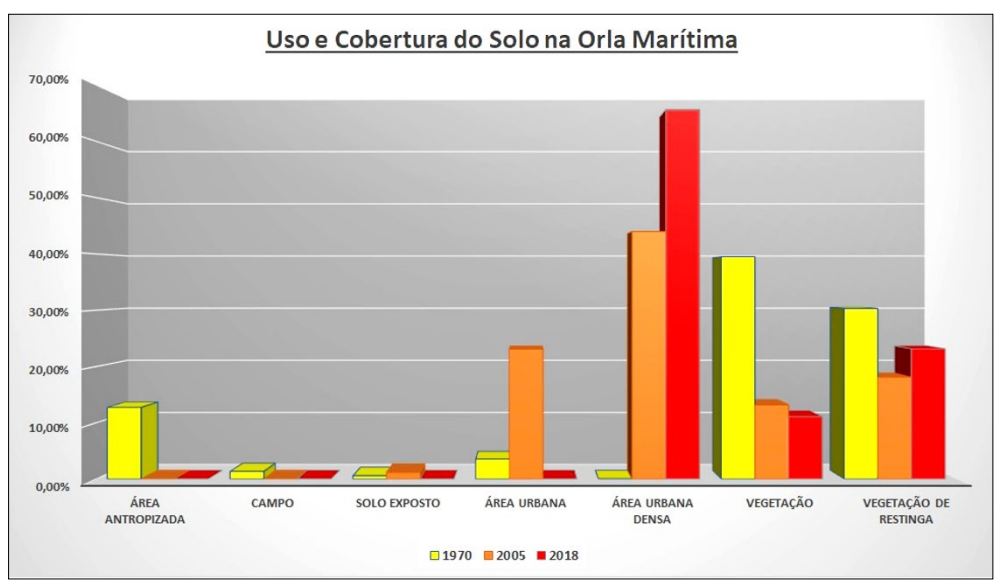

Em contrapartida, um nítido decréscimo pode ser percebido na vegetação desde 1970, ano em que o seu percentual de cobertura correspondia a 40\%, diminuindo para menos de 15\% em 2005 e chegando próximo dos 10\% em 2018. Possivelmente essa diminuição do percentual de cobertura da vegetação está correlacionada ao nítido aumento das áreas urbanizadas, devido a novos loteamentos e consequente aumento de construções dentro dos limites da orla marítima estipulada no presente trabalho. Enquanto isso, uma variação é notada nos percentuais que correspondem à vegetação de restinga, havendo, nesta classe, uma diminuição de seu percentual quando comparados os anos de 1970 e 2005, estando em torno de $30 \%$ o percentual de cobertura para o primeiro ano mencionado e abaixo dos $20 \%$ para o segundo ano. Um ligeiro aumento é percebido para o ano de 2018 em relação ao ano de 2005, superando a marca dos $20 \%$ de percentual coberto. Essas variações podem estar correlacionadas ao fato de moradores dos condomínios próximos ao 
ponto 2, setor sul do arco praial da área de estudo, removerem a vegetação de restinga para construção de benfeitorias à beira-mar.

Devido ao fato de os valores referentes às demais classes serem muito inferiores à representatividade do gráfico gerado em relação às classes mencionadas, estas não serão passíveis de nota.

\section{CONCLUSÕES}

A alta vulnerabilidade e susceptibilidade à erosão costeira encontrada no ponto 1, localizado mais ao norte do arco praial, pode ser corroborada também pelo grau de exposição a ondas de sudeste com alturas significativas de até $3 \mathrm{~m}$, como demonstram os resultados de Azevedo (2008) e Lins-de-Barros (2010), identificando hotspots através do modelo de propagação de ondas do software SisBaHiA. Numa menor intensidade, as ondas de sul-sudeste podem atingir a área do ponto 1, como demonstra o resultado de propagação de ondas gerado por Muehe et al. (2011) no mesmo software.

Apesar de os dados de Luijendjk et al. (2018) enquadrarem a área do ponto 1 como estável, há no seu próprio gráfico uma linha de tendência à erosão, por mais que esta seja sutil. Quando analisada em conjunto com os geoindicadores e um recuo recente da linha de costa (entre 2005 e 2018), possivelmente associada à intensificação da ocupação na orla marítima e pulsos erosivos por consequência de ondas de alta energia, acaba por reforçar a atenção para se gerir este setor da orla marítima, visto que sua resiliência ou capacidade de recuperação a esses eventos possa ser debilitada.

Os dados também sugerem que o ponto 2 se distingue do ponto 1 no que diz respeito à vulnerabilidade e susceptibilidade à erosão costeira, o que pode ser corroborado pelo grau de exposição, menos exposto à ação das ondas de sudeste, por estar numa região de sombra gerada pelo cabo Búzios, como ressaltam diversos autores (Azevedo, 2008; Linsde-Barros, 2010; Muehe et al., 2011), assim como pela leve tendência progradante apontada pelos dados de Luijendijk et al. (2018). Além disso, o padrão de ocupação neste ponto tornase mais afastado do perfil dinâmico praial, com a presença de duna frontal e desenvolvimento de vegetação de restinga.

Os geoindicadores abordados foram fatores essenciais para a compreensão do quadro de cada área, auxiliando na demonstração, a partir das classificações geradas, de quanto determinada área passa pela inerência de sofrer processos erosivos a partir de variáveis, como sua localização e estruturas em seu entorno, associada à ação de forças naturais e de agentes externos. Vale ressaltar que, dada a facilidade de levantamento dos geoindicadores como uma ferramenta de gestão da orla marítima, estes tornam-se importantes para avaliações rápidas e de baixo custo para análise da susceptibilidade e vulnerabilidade à erosão costeira (Magalhães, 2018).

Para ambos os pontos, a amplitude de variação no posicionamento da linha de costa ao longo de 48 anos se mostrou até a ordem de dezenas de metros, assim como os dados de Luijendijk et al. (2018) apontam para um período de 33 anos, indicando uma considerável variabilidade morfodinâmica provavelmente devido a efeitos de ressacas. Dessa forma, os dados não mostram claramente que o recuo da linha de costa é uma consequência de um processo de erosão costeira constante ao longo do tempo.

Entende-se que a zona costeira brasileira é reconhecida como Patrimônio Nacional na Constituição Federal e corresponde ao espaço geográfico de interação entre ar, mar e terra 
(incluindo seus recursos), abrangendo uma faixa marítima e uma faixa terrestre. O desenvolvimento de prioridades para as ações de ordenamento e gestão de zonas costeiras se dá pelas três esferas governamentais e do poder e de participação da sociedade civil organizada. A proposta de delimitação adotada pelo Projeto Orla combina os critérios de fragilidade e/ ou vulnerabilidade natural com as situações e os ritmos de ocupação e susceptibilidade.

O setor mais ao norte se mostra como uma área prioritária para ordenamento e gestão, pois, de acordo com os dados aqui abordados, esse setor possui um alto grau de exposição e edificações próximas ao perfil dinâmico praial, o que possivelmente pode vir a interferir nas formas naturais de como o perfil dinâmico se comporta, ainda mais quando analisado em conjunto como o indício de uma leve tendência retrogradante apontada pelos dados de Luijendijk et al. (2018) e o recente recuo da linha de costa acompanhando a intensificação da ocupação na orla marítima, o que se mostra relevante pelos registros do impacto das ondas em construções à beira-mar.

Logo, propostas de mitigação, preservação da vegetação de restinga, fiscalização e cumprimento da lei para que se mantenha uma distância segura das edificações em relação ao perfil dinâmico praial, assim como um programa de monitoramento da linha de costa e determinação da resiliência praial podem ser considerados como algumas das formas de se evitar os prejuízos à sociedade provenientes de eventos de ressacas nessa localidade.

\section{REFERÊNCIAS BIBLIOGRÁFICAS}

Azevedo, I.F. Emprego de modelagem computacional na simulação de processos morfo-sedimentares: o caso do embaiamento Rio das Ostras. Dissertação de mestrado, Programa de Pós-Graduação em Geografia, Universidade Federal do Rio de Janeiro, 127 p., Rio de Janeiro, 2008.

Boak, E.H. \& Turner, I.L. Shoreline definition and detection: a review. Journal of Coastal Research, v. 21, n. 4, 2005.

Bush, D.M.; Neal, W.J.; Young, R.S. \& Pilkey, O.H. Utilization of geoindicators for rapid assessment of coastal - hazard risk and mitigation. Ocean and Coastal Management, v. 42, p. 647-670, 1999.

Cowell, P.J. \& Thorn, B.G. Morphodynamics of coastal evolution, cap. 2, p. 33-86, in Carter, R.W.G. \& Woodroffe, C.G. (org.). Coastal Evolution. Cambridge University Press, United Kingdom, 1994.

Fernandez, G.B. \& Muehe, D. A influência de sedimentos fluviais na morfologia da praia e antepraia no embaiamento de Rio das Ostras - Cabo Búzios - (RJ). Geosul, v. 14, n. 27, p. 201-207, 1998.

IPCC. Summary for policymakers, in Pörtner, H.O.; Roberts, D.C.; Masson-Delmotte, V.; Zhai, P.; Tignor, M.; Poloczanska, E.; Mintenbeck, K.; Nicolai, M.; Okem, A.; Petzold, J.; Rama, B. \& Weyer, N. (eds.), IPCC Special Report on the Ocean and Cryosphere in a Changing Climate. In press, 2019.

Klumb-Oliveira, L.A. Variabilidade interanual do clima de ondas e tempestades e seus impactos sobre a morfodinâmica no embaiamento de Rio das Ostras - Cabo Búzios - (RJ). Tese de doutorado, Programa de Pós-Graduação em Geografia, Universidade Federal do Rio de Janeiro, Rio de Janeiro, 2015.

Lins-de-Barros, F.M. Risco, vulnerabilidade física à erosão costeira e impactos socioeconômicos na orla urbanizada do município de Maricá, Rio de Janeiro. R. B. G., v. 6, n. 2, p. 83-90, 2005. 
Lins-de-Barros, F.M. Contribuição metodológica para análise local da vulnerabilidade costeira e riscos associados: estudo de caso da Região dos Lagos, Rio de Janeiro. Tese de doutorado, Programa de Pós-Graduação em Geografia, Universidade Federal do Rio de Janeiro, 297 p., Rio de Janeiro, 2010.

Luijendijk, A.; Hagenaars, G.; Ranasingher, R.; Baart, F.; Donchyts, G. \& Aarninkhof, S. The State of the World's Beaches. Nature, Scientific Reports, 2018. Disponível em: https://www. nature.com/articles/s41598-018-24630-6.

Magalhães, B.L. Dinâmica da linha de costa e vulnerabilidade à erosão costeira nos arcos de praia da Tartaruga e de Costa Azul (Rio das Ostras, RJ). Dissertação de mestrado, Programa de PósGraduação em Geografia, Universidade Federal Fluminense, 77 p., Rio de Janeiro, 2018.

Muehe, D.; Fernandez, G.B.; Bulhões, A.M.R. \& Azevedo, I.F. Avaliação da vulnerabilidade física da orla costeira em nível local, tomando como exemplo o arco praial entre Rio das Ostras e Cabo Búzios/RJ. Rev. Bras. Geom., v. 12, n. 2, p. 58, 2011.

Muehe, D. (org.). Erosão e progradação no litoral brasileiro, Brasília: MMA, 476 p., 2006.

Piatto, L. \& Polette, M. Análise do processo de artificialização do município de Balneário Camboriú, SC, Brasil. Rev. Ges. Cos. Int., v. 12, n. 1, p. 79-90, 2012.

Rocha, T.B.; Fernandez, G.B. \& Nascimento, L.C. Avaliação dos critérios morfodinâmicos para a fase de diagnóstico do Projeto Orla: um estudo de caso em praias arenosas com desembocaduras fluviais. Soc. E Nat., Uberlândia, v. 25, n. 2, p. 333-348, 2013.

Silva, L.H.M.M. Modelo de análise para o entendimento do processo de artificialização do litoral. Estudo de caso da praia de Jurerê Internacional - Florianópolis (SC) e a Praia Central de Balneário Camboriú (SC). Trabalho de conclusão de curso, Faculdade de Oceanografia, Universidade do Vale do Itajaí, 186 p., Itajaí, 2007.

Souza, T.A.; Bulhões, E. \& Amorim, I.B.S. Ondas de tempestade na costa norte fluminense. Quaternary and Environmental Geosciences, v. 6, n. 2, p. 10-17, 2005. 